\title{
Epileptic Electric Power Generation and Supply in Nigeria: Causes, Impact and Solution
}

\author{
Johnson Olaosebikan Aremu \\ Department of History and International Studies, Ekiti State University, Ado-Ekiti, P.M.B. 5363, Ado- Ekiti, Nigeria. \\ Email: johnsonolaosebikan@gmail.com
}

Received: 24 May 2019; Revised: 26 June 2019; Accepted: 5 July 2019; Published: 29 July 2019

\begin{abstract}
This paper examines the challenge of epileptic electric power supply in Nigeria since independence till date. The paper observes that a majority of Nigerians now pay excessively for darkness as they experience power outage for an average of 20 hours daily, while their estimated billing has continued to increase astronomically, unabated. This has impacted negatively on the socio-economic development of the country and is currently inciting conflicts between the electricity distribution companies and aggrieved consumers across the country. In view of the above, the paper identified some factors responsible for this ugly development and highlights some of its effects on Nigeria's economy. Data for the study was obtained through oral interviews with electricity consumers (especially in Ekiti, Osun and Oyo states) and officials of Ibadan and Benin Electricity Distribution Companies; personal observations; group discussion method; and a rigorous library search of related literature. The study employed the descriptive and analytical qualitative methods of historical research to analyse its data. It recommends that electricity supply should be given necessary attention by the government to enable the country harness her rich human and material resources.
\end{abstract}

Keywords: Electricity, Nigeria, Power sector, Infrastructures, Economy

\section{Introduction}

Electric power is the most common source of energy in contemporary world history. This explains why it plays a pivotal role in the industrial and technological development of nations across the globe. As such, any country that is desirous of sustainable development in this age of technology must, as a matter of necessity, device means of regular generation and effective power supply. Without it, meaningful socio-economic as well as industrial development of any kind cannot be achieved. Apart from this, efficient electricity supply impacts positively on other facets of human existence in the modern world, most especially in vital areas like; commerce, education, communication and the general standard of living (Urrutia, 1965:161). It is in view of the above that this paper examines the problem of inadequate and irregular electric power generation and distribution in Nigeria, since independence. According to Ohajianya etal (2014:55), Nigeria generates an average of 3,600 megawatts of electricity for a population of about 150 million as at 2014. This is abysmally low and grossly inadequate when compared to what obtains in some other African countries like South Africa and Ghana where an average of 40,000 and 2,111 megawatts of electricity was generated for a population of 50 million and 23.84 million respectively during the same period (Ohajianya etal, 2014:55). This perhaps accounts for the consistent poor supply of electricity across the country over the years. Consequently, this paper investigates the causes of epileptic power supply in Nigeria, its impact on the socio-economic fortunes of the country and ways of improving the capacity for electricity generation and supply in the country.

\section{Statement of the Problem}

Electricity supply in Nigeria has been highly epileptic since independence. Despite the various intervention programmes and projects instituted by the Federal government over the past years, power generation and supply have not witnessed any significant improvement. For instance, in 2005 President Olusegun Obasanjo introduced the Electricity Power Sector Reform (EPSR) Bill to the National Assembly. It was enacted into law in 2006 (Ndugbu, 2011:23; Okolo and Etekpe, 2011:33). Some of the provisions of the Law are: 
i. Establishment of the Power Holding Company of Nigeria (PHCN) which inherited all assets and liabilities of the defunct National Electric Power Authority;

ii. Appointment of a legal firm by the Bureau of Public Enterprises (BPEs) to set up successor companies and privatise the unbundled entities;

iii. Establishment of the Nigeria Electricity Regulatory Commission (NERC);

iv. Commencement of rural electrification project (REP);

v. Establishment of a Power Consumer Assistance Fund (PCAF) to subsidise less privileged power consumers, including both rural and urban poor citizens (Federal Republic of Nigeria (2005), cited in Ezirim, etal, 2016:444).

Obasanjo's successor, Umaru Musa Yar'Adua, later went ahead to make power as one of his Seven Point Agenda and even declared an 'emergency' in the power sector. Goodluck Jonathan's administration equally introduced the Roadmap for the Reform of the Power Sector in 2010. Its central focus included privatisation and metering of all consumers to address the challenge of poor electricity in the country. All these reforms, however, failed to achieve their desired goals. Ndugbu (2011:23) suggests that the reforms failed due to lack of patriotism among top-ranking government officials in affected ministries, agencies and ministries which frustrated the lofty agendas of government.

Today, individuals, communities and companies are fully responsible for the installation of electricity in their homes and business premises. This involves buying the electric poles, cables and transformers as well as paying for their installations. All that the electricity regulatory agencies do are to: issue bills, albeit irrationally based on estimation, collect electricity tariffs and disconnect users for whatever reasons best known to the so called 'electricity providers'. To compound the situation, these electricity regulatory bodies have a tradition of increasing electricity tariff incessantly and exorbitantly at will. Unfortunately, they have refused to make any supply of electricity to most locations (such as Igede-Ekiti and Erijiyan Ekiti in Ekiti state; and Ikire in Osun State who all shared the same experience of being in total black-out for periods ranging from three (3) to five (5) years in a row).In the few cases of availability, they have provided very abysmally low currents. The situation has degenerated to the extent that some locations that were hitherto envied for enjoying regular and efficient electricity supply like Osogbo, Ifon and Ikirun in Osun state are now experiencing regular power outage like other communities. Indeed today, Nigerian electricity consumers may be said to be paying more for darkness. What then are the causes of this incessant power outage in Nigeria? What are its effects on the Nigerian economy at large and what can be done to salvage the situation? These and other related matters are problematic this paper is set to resolve.

\section{Historical Survey of Electricity Generation and Supply in Nigeria}

Electricity, as a source of energy, was introduced into Nigeria by the British colonial authority in 1896 (Sule, 2010: 160; Onochie, etal, 2015:494). It was intended mainly to provide illumination and to preserve certain food items and drugs (Adebare, 1975: 298). In the post-second World War era, however, colonialism came under severe international attack as it was accused of exploitation without any significant impact on the development of the colonies and improved condition of living for the people therein (Oliver, et al. 1983:2 13). In response to the above criticism, the British Colonial Administration initiated the Colonial Development and Welfare Act of 1940 with a view to initiating reforms in their colonies, particularly in West Africa (National Archive Ibadan, File 1/1/470). The Colonial government also initiated some development plans with focus on rural development, rural health, agricultural extension services and development of local industries in 1945. To accomplish all these, there was the need to restructure and re-energize electricity supply in the country.

By 1950, isolated generating stations had been built in Lagos and some provincial headquarters in Nigeria which generated electricity from diesel oil and coal (Adebare, 1975:298). But with time, hydro sources became the preferred choice for multiple reasons. In the first instance, water energy does not involve the haulage of fuel from one location to the other as it is sourced from natural source which could be tapped indefinitely. Furthermore, the country, particularly the southern part, is blessed with abundant supply of water with which hydro-energy could be generated easily at minimal cost. Beeka (1975:80) also points out that:

Small hydro stations of 50 megawatts units or less can be located here and there, all over the southern part of the country and possibly around Lake Chad, more so that Nigeria's network of rivers show over fifty rivers with a reasonable head and catchment areas that can be developed for hydro power. 
Other benefits derivable from hydro-electric source of power include irrigation farming and fishing. These, perhaps, made Thomas (1975:91) to conclude that "hydro-electricity is symptomatic of an advanced stage of industrialization and socio-economic development".

\section{Electricity Management in Nigeria: The Agencies Involved}

As a result of the emerging needs for electricity in colonial Nigeria, the imperial administration set up the Electricity Corporation of Nigeria (ECN) in 1950 as a statutory controller and operator of electricity generating and distributing mechanisms that were put in place in many areas in the country (Sule, 2010: 160). By 1958 , the ECN was producing approximately $80 \%$ of the 343 million units generated, while the others were sourced from other generating systems (National Economic Council. 1959:55). As a result of the wide dispersion of the generating systems scattered over Nigeria and the low maximum demand, electricity generation and distribution was considered capital intensive as interconnectivity was almost impossible. This made the Colonial government to adopt the report of the International Bank Mission, published in 1954 which recommended that the Electricity Corporations should concentrate power supplying to areas with relatively high industrial and consumers' needs and that it should postpone the opening of new plants in towns not already served. As a result of this recommendation, extensive electrification of most parts of the country was put on hold so that fifty per-cent of the total output of the Corporation could service Ibadan, Abeokuta, Osogbo and Lagos (National Economic Council. 1959:55).

With the attainment of independence in 1960, Nigerian government initiated some policies with focus on industrial development and expansion. This led to the establishment of the Industrial Development Commission of Nigeria (IDCN) to promote and foster industrialization throughout the country. In line with the Economic Survey of Nigeria, 1959 (National Economic Council. 1959:55), it was projected that the generation and supply of electricity capacity by the end of 1962 should double what it was (National Economic Council. 1959:55). Unfortunately, however, this projection turned out to be a mirage. By 1962, through an Act of Parliament No. 23 of 1962, the Niger Dams Authority (NDA) was set up for the construction and maintenance of Kainji Dam (Awosope, 2014: 5). Through this, it was projected that the NDA would supply electricity to Lagos, a large portion of the Northern Region and the bulk of Western Region, thereby solving, to a large extent, the problem of power outage in the country. It was also viewed that the scheme would improve navigation on the Niger River as well as contributing to the development of agriculture by providing effective irrigation and flood control systems (ibid).In the same year, ECN extended the supply of electricity to thirty-eight new towns, twenty seven of which would be supplied from the existing generating stations and the remaining eleven by new stations which would have a combined initial capacity of 3,900 Kilowatts (ibid). The benefiting towns in these schemes included Owerri, Akure, Bauchi, Gombe, Lokoja, Makurdi, Ilorin, Ogbomoso, Nsukka and Oyo. It was also decided that four rural electricity schemes be established to test the validity of the economics of supplying electricity to rural areas (ibid). With all these, it was obvious that the government of Nigeria had good intention towards nationwide electricity supply.

In 19681968, the first phase of the Kainji Dam, Nigeria's first hydro-electric power source, was commissioned with the installation capacity of four plants of 100,00ohorsepower, Kaplan type Turbines, which drives generator rated at 80Mwk 85MVA output (Federal Department of Information. 1987:49). This was designed to supply most of the power need of the country. Soon afterward, the power required had increased beyond the output of the available installations. This necessitated the establishment of Onitsha, Zunguru and Katsina-Ala's hydro-electric power projects. Subsequently, Lokoja, Ijora, Delta, Afam, Ikom, Makurdi, Sapele, Port-Harcourt, Shiroro and Jebba hydro power projects were added to the available sources. All these moved the installed capacity of electricity in Nigeria to 6,942gigawatts even till the early 1990s (Federal Department of Information. 1987:49). Unfortunately, owing to inefficiency and other challenges, the electricity mirage continued as there has always been a wide disparity in the installed and available capacity of electricity in Nigeria. For example, by the year 2001, the installed capacity was about 10,396-0 megawatts while the available capacity was only 6,056 megawatts. These deficiencies manifested in 1967, when a team of 16 Canadian engineers, technologists and technicians led by R.D. Nevison was sent by the Ontario HydroElectric Power Commission to help in operating the Kainji Dam Power Plants and concurrently train Nigerians to take over the operations and maintenance of the plant (Ade-Ajayi, 1995: 85-86). Laudable as this projection was, as early as 1970 , these indigenous engineers who had taken over the operations of the Dam had started to complain of inadequate funding, which the foreign engineers did not suffer and which was required to build up the kind of facilities needed to place their operations and output on equal level with what operated in European nations. Unfortunately, not much was done to redeem the situation. 
The National Electric Power Authority (NEPA) came into existence on 1 April 1972 when the Electricity Corporation of Nigeria (ECN) and the Niger Dams Authority (NDA) were merged to form a single electricity generating, distributing and management body (Onochie, etal, 2015:494). Its statutory function was to develop and maintain an efficient, well coordinated and economically viable system of electricity supply throughout the nation. It had a total monopoly on all commercial electricity supply and was responsible for the production, transmission and distribution of electricity to end consumers (Idris, etal, 2013:2). According to Ohajianya etal (2014:51) it generated electricity from eight power stations as follows:

a. Ijora Thermal Power Station established in 1956

b. Afam Thermal Power Station established in 1962

c. Delta Thermal Power Station established in 1966

d. Kanji Hydro Power Station established in 1968

e. Ogorode Thermal Power Station established in 1980

f. Jebba Hydro Power Station established in 1985

g. Lagos Thermal Power Station established in 1986

h. Shiroro Hydro Power Station established in 1989.

This, however, did not prevent private individuals or organizations from generating power through thermal plants or other sources for domestic use (Ade-Ajayi, J.F.A. 1995:85-86). In spite of the heavy financial investments on NEPA, the incidence of power outages persisted and this compelled the Federal Government to enact the Electric Power Sector Reform Act (EPSRA) that was signed into law on 11 March 2005. The new law granted the ownership of electric companies to the Bureau of Public Enterprises (BPE), through the CPCS, Transcom Limited, Ottawa Ontario. It also established the Nigeria Electricity Regulatory Commission (NERC) to monitor the electricity reform process and established the Power Holding Company of Nigeria (PHCN) to replace NEPA. The law further directed the new agency to embark on the privatization of electricity generation and management in Nigeria. Consequent upon this, eleven electricity distribution companies were appointed in 2013. These are: Abuja, Benin, Eko (Lagos), Enugu, Ibadan, Ikeja, Jos, Kaduna, Kano, Port-Harcourt and Yola Distribution Companies. Consequently, from 30 September 2013, PHCN ceased to exist in Nigeria (Ohajianya etal, 2014:51).

\section{Causes of Inefficient Electricity Generation and Distribution in Nigeria}

The quest for industrialization and socio-economic development in Nigeria will remain a mirage unless critical steps are taken to eradicate the erratic and unreliable supply of electricity for industrial and domestic uses. It is pathetic to note that in spite of the various policies and programmes initiated by successive administrations in the country to overcome the challenge, as well as billions of public fund invested in the various intervention projects, the output of these electricity companies remain extremely poor and this has retarded effective exploitation of the numerous economic potentials of the nation. To attain the required level of electricity supply for industrialization, it is necessary to investigate the challenges that confronted the electricity generating bodies with a view to proffering solution to them.

Olofin (1975: 307) blames the ineffective power supply in Nigeria on the concentration of vital functions of production, distribution and marketing on the same body. Since Nigeria is exposed to numerous sources of energy which include hydro and thermal, production of electricity should be decentralized to enable interested organizations embark on its production and sales, without cumbersome bureaucratic bottlenecks. It is unfortunate that this suggestion was not taken, even with the privatization of electricity generation in Nigeria, the licenses for its operation were granted to certain identified companies with monopoly to oversee its production in certain geographical areas. With this, it can be inferred that the existing monopoly in the production and distribution of electricity is still as of old. It is, therefore, not surprising that the inefficiency and lack-luster performance noticed in the pre-privatization era, still conspicuously characterize the activities of the appointed electricity bodies.

The geographical spread of Nigeria has also been mentioned as a problem confronting electricity supply (ibid). The vastness of the territory, the expanding tendencies of industrial output and the adoption of multistate structure, all combined to compound the problem as the generating bodies seems to be incapable of coping with the rising needs of Nigerians in this regard.

The cumulative effect of inadequate planning and the virtual absence of an integrated national fuel policy in Nigeria also compound the problem of electricity. Although, the country has initiated various development plans which would have imparted positively on its overall advancement, surprisingly, such was not achieved owing to deficiencies in the development plans and absence of political will by the successive government to 
execute the content of the plans with dedication and commitments. The prospects of fiscal self-sufficiency which arose from the "oil boom" of the 1970s could have been used to lay a solid foundation for the socioeconomic development of Nigeria through the revitalization of the core sectors of the economy. Unfortunately, the nation's expenditure, at that period, went into private consumption as the ruling class had unlimited access to the national treasury and, therefore, squandered the resources on luxurious cars, imported foodstuff, precious ornaments and other imported materials (Okoye, 1973: 20). Consequently, the Second and the Third National Development plans (1970-1974), which could have expanded developmental efforts along the line of economic internalization failed to realise its stated objectives.

Over-reliance on hydro-electric power has also been identified as one of the constraints to regular electricity supply in Nigeria. Although, water energy was considered cheap, available and accessible by electricity planners in the country, this source of energy was confronted with serious problems as many of the available rivers possess low-head at some months of the year, thereby reducing the output of the generating installations. As a result, Nigeria electricity providers could have considered this and given due attention to other sources, particularly thermal sources such as coal, crude oil, natural gas, nuclear fusion and solar energy, if only to augment the output of hydro-power.

Many experts have also raised the issue of low technology and manpower as terrible logs in the wheel of effective electricity generation, distribution and supply in Nigeria. This cannot be disputed as the electricity managing bodies relied mainly on foreign experts for the installation and maintenance of their equipments. This, by implication, made them to accept whatever these foreign experts could give, however, obsolete and unreliable such could be (Olofin, 1975: 307).

Excessive importation of generators into the country is another factor. Nigeria's borders are open to different brands of imported generators. These range from low and medium capacity to heavy duty/ industrial generators. It is essential to note that importation and use of generating plants is expected to be a coping strategy and short-run bail-out mechanism out of the predicament of power outages by individuals, corporate bodies and industries in the country. Unfortunately, this has become a norm in the country as almost every household and industry rely substantially, if not totally, for their power supply today. This supposedly palliative measure has indeed become a bane to solving the problem of epileptic power supply in Nigeria. The most important reason for this is not farfetched. All the importers of generators in the country are bourgeois, few rich individuals who are either politicians or business magnates that make a lot of profit from the business. To maintain their economic stronghold on the nation and thus protect their own capitalist interests of exploitation, they have collectively frustrated every attempt at restoring effective power generation and distribution in the country. This may continue for long if government fails to control the importation of generators into the nation.

Poor maintenance culture is another challenge facing effective power generation and distribution in Nigeria. It is a truism that there is a near absence of maintenance culture in Nigeria at large. This is highly pronounced in the power sector. Available records indicate that electricity generation and distribution began in Lagos in 1869 (Okolo and Etekpe, 2011:36). By 1965, several power generation stations have been constructed across the nation to provide electricity to the teeming population. This trend has continued till date. It is, however, disheartening to note that various agencies of government, including the Federal Ministry of Power and Energy, as well as electricity generation and distribution companies such as the defunct NEPA/PHCN and the current eleven electricity distribution companies have exhibited a sense of lack of maintenance culture. For instance, most of the transformers are aged and dilapidated, crying for replacement; the electric wooden poles are either decomposing or already decomposed in most cases; the cables are old and break very often; while almost all the surveillance vehicles for monitoring and rectifying faults are grounded. Even more pathetic is that NEPA/PHCN/BEDC offices (in Ado-Ekiti, for example) run on generators! The power plants, equipments and facilities are obsolete and need urgent replacement and subsequent regular maintenance to boost regular power supply in the country.

Perhaps the most debilitating challenge to effective power generation and distribution in Nigeria is systemic corruption among senior government officials in affected ministries and parastatals. Several billions of dollars pumped into the power sector have either been embezzled or misappropriated by state officials. Most of these investments have gone down the drains. The effect is that government has severally succeeded in spending much to achieve little or nothing in the power sector.

Among other problems that have been identified as responsible for poor performance of electricity supply in Nigeria include: bureaucratic bottlenecks involved in its attachment to the Ministry of Power, manpower shortage and poor distribution mechanism, low tariff, financial restraints, vandalisation of power 
infrastructures, apathy towards settlement of electricity bills due to excessive and irrational billing by distribution companies and; corruption among public servants in the energy sector.

\section{Effects of Poor Electricity Generation and Supply on Nigeria's Economy}

The poor state of electricity generation and supply in Nigeria has had some negative impacts on the nation's economy in a number of ways. In the first instance, small and medium scale enterprises have been rendered largely inefficient and ineffective in the country. This is because most of these business ventures are highly dependent on electricity to survive and make profit. Since most of the owners are relatively financially poor and power supply is erratic, some of them became insolvent due to excessive expenses on generator purchase, fuelling and maintenance. With time, they were forced to close down with most of the owners running at a loss and sometimes becoming insolvent.

Furthermore, the absence of regular supply of functional electricity has also led to high cost of production of goods and services. According to Ndugbu (2011:15), a great number of industries (small, medium and largescale alike) spend about60\% of their annual budgets on power generation. Large scale industries have even taken a step further in this direction. Most manufacturing companies have procured their own transformers all in a bid to sustain regular production as a result of functional power supply. Though this strategy had proved effective, power supply by electricity providers have been largely irregular. This informs why all reasonable manufacturing companies in the country have further invested heavily in heavy duty/high capacity generators to enhance their production capacities. It is essential to stress that the use of generators is always at an exorbitant cost to the companies, including that of purchase, fuelling and maintenance. Maintaining two sources of energy simultaneously drastically reduces the companies' cash flows and operating costs. This has led to high cost of production and made their finished goods very expensive as against imported goods in the country. Customers' patronage has been very low resulting in low profit margins over time.

Related to this is that erratic power supply led to the exit of some locally owned and major multinational companies hitherto operating in the country, impacting negatively on industrial growth and development of the nation. Since the late 1990s, the exodus of Nigerian companies and manufacturers to Ghana has been very alarming. Examples include Michelin and Dunlop, two giant tyre manufacturing companies operating in Nigeria since 1963 and 1965 respectively; and other Nigerian-owned businesses, including insurance companies, banks, oil and telecommunications companies (Aremu, 2013:268-269). It is true that a number of explanations have been offered for the movement of these businesses to Ghana since the mid-1990. These included the purported desperate attempts by Ghanaian authorities to lure Nigerian manufacturers to Ghana. The drive involved mouth-watering packages such as 15year tax holiday and free land, lack of bureaucratic bottlenecks in the processing of investment formalities, availability of investment capital at low cost, cheap cost of funds, low operating costs, higher business returns in Ghana than what obtains in Nigeria, as well as excellent manpower and skilled workers to meet the needs of manufacturers, among others (Aremu, 2013:269).

But, without prejudice to the logicality of the above explanations, the reality is that the regularity of power supply in Ghana over the past two decades served as the greatest source of attraction to Nigerian businesses. This is in contrast to the erratic nature of power supply in Nigeria which has been the bane of industrial development in the country.

The exit of these numerous viable industries from Nigeria has brought about an escalation of rate of unemployment in the country. It led to high incidence of mass retrenchment of staff, turnig thousands of Nigerian workers back to the labour market. This also increased the dependency ratio in the country. This further led to an escalation of crime rate in the immediate post-exit period of the affected companies. Another corollary effect was increased level of poverty in the country. Since most of those retrenched were the bread winners in their respective homes, poverty immediately set in just as standard of living deteriorated significantly. Life has been very traumatic for some of the victims ever since then.

Another effect of poor electricity distribution in Nigeria is that of incessant imbroglio and conflicts between electricity distribution company workers and aggrieved consumers. These consumers are usually youths, though with the backing of some elderly persons. Most often than not, the staff of these companies have been subjected to premeditated attacks in students' dominated environments. Some of the ensuing conflicts have been fatal leading to the death or maiming of electricity workers and the youths. Perhaps the most potent source of such conflicts has been refusal or inability to settle electricity bills by affected consumers and the resilience of electricity workers to disconnect affected households from electricity supply. It is interesting to note that non-payment of electricity bills has been more of a collective decision and action by consumers to register their displeasure against irrational billing system by electricity companies in the face of 
glaring erratic or in most cases, none supply of electricity to affected areas. For instance in Ado-Ekiti, the capital of Ekiti state, the landlords association has recently formed a joint body to fight what they refer to as "great injustice of paying more for darkness" suffered in the hands of the Benin Electricity Distribution Company (BEDC). Some of their demands are a drastic reduction of electricity bills from fourteen thousand, three hundred naira (\#14,300.00k) monthly to three thousand, one hundred naira per house unit. They are also demanding immediate metering of unmetered units by the BEDC. Apart from instituting a legal case against BEDC, they addressed a press conference and staged a peaceful protest in January 2018 to press home their demands. . Just of recent, on 3 October 2018, they issued a public announcement that no household should pay more than \#3,100 naira as electricity bill until all their demands are met. It is observed, however, that the BEDC has deliberately disconnected consumers who paid less than \#5,000.00 monthly. This is the experience of consumers in Abuja quarters, GRA extension and Awedele areas as at first week of October, 2018. The above detailed narrative is essential to draw home the fact that an impending electricitydistribution-and-billing-induced conflict may be looming in Ado-Ekiti, if care is not taken. It should be recalled that similar protests by consumers took place recently in Igede-Ekiti, Iyin-Ekiti, Ikere-Ekiti and Ikole-Ekiti. Some of the protests were led by Kings of affected communities and have resulted into the sacking of electricity workers from affected areas, though temporarily; as well as looting and arson.

The absence of regular supply of electricity is also responsible for the increasing noise and air pollution in the country. Almost every household and business center owns at least one generator in Nigeria. As such, noise and air pollutions have become daily occurrences in Nigeria. Though the impact is more in urban centers, the rural areas are not spared of the attendant negative health and environmental impact of the noise and air pollution. Only God can save the country from these hazards as various environmental friendly regulations made by government to curb these problems have not been effective.

It is apt to add that the problem of incessant black-out has also dissuaded foreign investors from coming to Nigeria. Since the main motive of any business organization is to maximize profit, the high cost of doing business in Nigeria, particularly in the area of running machines with diesel- powered generators, as adjudged by the experience of some previous organisations in the country, has served as a deterrent to would-be investors from coming to establishing industries in the country. This has brought about stagnation in the economic growth profile of the country.

Other impacts of the challenge of erratic electricity supply include the high incidence of corruption among experts and bureaucrats in the power sector and workers of electricity companies. The list is in-exhaustive.

\section{The Way Out}

In the previous sections, I have catalogued some of the causes and effects of epileptic electric power generation and distribution in Nigeria. In this section, some of the possible solutions to the identified challenges are identified.

Perhaps the base line of any solution to the epileptic power supply in Nigeria is to declare an emergency in the power sector. This was done by the late President Umaru Musa Yar'Adua. However, the policy implementation was truncated due to his untimely death in 2009. The Nigerian government needs to take drastic actions to appraise and restructure the power sector architecture of the country. This will involve appointing experts to head the Ministry of Power instead of the kangaroo appointment of trained lawyers instead of professional electric power experts to head the Ministry as was done by President Olusegun Obasanjo and Muhammadu Buhari's civilian administrations. It will also require a strong political will to carry out viable reforms in the power sector over time including a purge of unnecessary dead loads in its personnel profile. This is because; the provision of cheap, stable and reliable power supply is the foundation of sustainable economic development in the new world economic order. In its absence, economic development is stunted.

Apart from this, drastic steps must also be taken to confront and suppress the rampant scourge of corruption in the power sector. As long as the corrupt officers are still on ground, there is no amount of reform that can bring any tangible transformation in the sector. Government should realize that these corrupt officials operate like a cabal and may thus be difficult to track down easily. They are mighty looters who feed fat on the inefficiency of the power sector and who are ready to sabotage any laudable reform method for their own selfish interests. In this wise, concrete plans and strategies must be put in place to identify, apprehend and flush out the high and mighty behind the inefficiency in the power sector. There should be no sacred cow in the exercise. Anti-graft agencies must be empowered to carry out this task in the most efficient and professional manner without fear or favour. 
In a similar dimension, Government and the electricity regulation, generation and distribution agencies and companies must collaborate to replace existing obsolete power equipments and facilities with new and modern equipments and facilities throughout the nooks and crannies of the country. This will no doubt attract very huge expenses. Hence, there may be the need to have a special dedicated fund created for this laudable project. It should be regarded as a lifetime investment that will surely yield great dividends to the economic buoyancy of the country in a very short distance of time. New, un-captured areas should also be incorporated in the scheme of things. Once this is done, government must institute a new maintenance culture to make the system work effectively and efficiently. They must ensure proper maintenance of electricity equipments and facilities such as poles, cables, transformers and vehicles among others. The surveillance, monitoring and maintenance units of electricity regulatory agencies should also be equipped with modern technological gadgets to detect and rectify faults on time and probably reduce incidence of vandalisation of electricity facilities.

Another important step to be taken to ensure the efficiency of the power sector is to provide pre-paid meters for all households and customer outlets and thus eliminate the estimated billing system that operates in the country today. This is to enhance an effective revenue generation drive by the distribution companies as it will reduce bottlenecks in the billing-payment system. It will also promote equity and fairness in the payment system as far as customers are concerned. This is also expected to reduce, if not totally eliminate, the recurrent frictions between electricity distribution companies and their customers over the challenge of excessive estimated billing system.

\section{Conclusion}

It has been asserted that electricity generation and supply has been below expectation in Nigeria during the period of study. Uninterrupted power supply has indeed been a mirage in the nation's history. This has retarded economic growth and development in the country. The situation is so bad that some multinational companies like Dunlop have relocated to other countries citing inefficient electricity supply as a major push factor. Locally owned industries, especially in the manufacturing sector, have suffered stagnation and outright extinction as a result of the abysmal supply of electricity. The same fate has been the lot of numerous medium and small scale enterprises in Nigeria. This ugly development has led to numerous job losses among Nigerian youths over the years. Dependency ratio has increased significantly while poverty level is on the rise.

Judging from the above, the Federal Government of Nigeria needs to be pro-active to stem this unpalatable development if the country will not remain an underdog in the global competition for industrialization and improved standard of living. To this end, there is the need for a comprehensive review of the nation's electricity policy. Government should also be willing to checkmate the rampant scourge of corruption that is taking its toll on Nigeria's efforts at re-positioning the power sector for better efficiency. The various electricity generation and distribution companies must also be given close monitoring to ensure adequate performance. Similarly, they should be compelled by law to issue prepaid meters to all customers within a very short 'reasonable' period of time. Apart from that, the power distribution companies should be encouraged to employ competent and qualified staff for timely discovery and rectification of faults. A sustainable maintenance culture of electricity equipments and installations across the country is also recommended. New power generation stations must also be constructed and connected to the National Grid to boost power supply in the country. This will no doubt enhance the regularity of power supply in the country and thus overcome the challenge of incessant power outages that the nation is battling with at present.

\section{References}

Adebare, A. (1975). The Reorganization Envisaged in Electricity Supply Industry. In Proceedings of The Energy Policy Conference held on $2^{\text {nd }}-4^{\text {th }}$ August, 1975 at Jos, Nigeria.

Ade-Ajayi, J.F.A. (1995). History of the Nigerian Society of Engineers. Lagos: National Engineering Centre.

Aremu, J.O. 2013. Nigeria-Ghana Diplomatic Relations, 1960-1999. Unpublished Ph,D Thesis, Ekiti State University, Ado-Ekiti.

Awosope, C.O. (2014). Nigeria Electricity Industry: Issues, Challenges and Solutions. Covenant University $38^{\text {th }}$ Public Lecture Series, Vol. 3, No. 2, October. Ota: Covenant University Press.

Beeka, E.D.Z. (1975). 100 Years of Cheap and Continous Power Strategy in Nigeria. In Proceedings of The Energy Policy Conference held on $2^{\text {nd }}-4^{\text {th }}$ August, at Jos, Nigeria.

Ezirim, G., Eke, O. and Onuoha, F. (2016). The Political Economy of Nigeria's Power Sector Reforms: Challenges and Prospects, 2005-2015. Mediterranean Journal of Social Sciences, 7(4): 443-453.

Federal Department of Information. (1987). Saga of Progress in Nigeria, 1960-1985. Lagos: Samdegraphic Limited. 
Federal Republic of Nigeria (2005). Electric Power Sector Reform Act. Official Gazette, 92(77).

Idris, A., Kura, S.M., Ahmed, M.A., and Abba, Y. (2013). An Assessment of the Power Sector Reform in Nigeria. International Journal of Advancements in Research \& Technology, 2(2): 1-37.

National Archive Ibadan, File 1/1/470. Correspondence No 777/18 of $26^{\text {th }}$ November, 1945.

National Economic Council. (1959). Economic Survey of Nigeria. Lagos: Federal Government Printers.

Ndugbu, M.O. (2011). Poor Infrastructure and Insecurity: A Major hinderance to Manufacturing in Nigeria. CIRSD International Journal of Development Studies, 3(2): 13-28.

Ohajianya, A.C., Abumere,O.E., Owate,I.O. and Osarolube, E. (2014). Erratic Power Supply in Nigeria: Causes and Solutions, International Journal of Engineering Science Invention, 3(7): 51-55.

Okolo, P.O. and Etekpe, A., (2011). A Study of Public Maintenance Culture and Its Impacts on the Socio-Economic Development of Nigeria, 2005-2009. CIRSD International Journal of Development Studies, 3(2): 29-46.

Okoye, M. (1973). Politics and Problems of the First Republic of Nigeria. Ile-Ife: Faculty of Arts Lecture Series, University of Ife.

Oliver, R. et al. (1983). Africa Since 1800. 3rd Edn., Cambridge: Cambridge University Press.

Olofin, E.A. (1975). Making Electricity Energy Profitable in Nigeria. In Proceedings of The Energy Policy Conference held on $2^{\text {nd }}-4^{\text {th }}$ August, at Jos, Nigeria. pp: 307.

Onochie, U.P., Egware, H.O., and Eyakwanor, T.O. (2015). The Nigeria Electric Power Sector: Opportunities and Challenges. Journal of Multidisciplinary Engineering Science and Technology, 2(4): 494-502.

Sule, A. H. (2010). Major Factors affecting Electricity Generation, Transmission and Distribution in Nigeria. International Journal of Engineering and Mathematical Intelligence, 1(1\&3): 159-164.

Thomas, M.A. (1975). Energy and Energy Sources in Nigeria. In Proceedings of The Energy Policy Conference held on $2^{\text {nd }}-4^{\text {th }}$ August, at Jos, Nigeria.

Urrutia, R.V. (1965). Electricity Power Requirements in Urban Expansion. Conference Proceedings of American Society of Civil Engineers. Theme: The Civil Engineers in Urban Planning and Development. Pueto Rico, October 2830. 